\title{
Improving environmental benefits of white clover through condensed tannin expression
}

\author{
Derek R. WOODFIELD ${ }^{1}$, Marissa B. ROLDAN ${ }^{2}$, Christine R. VOISEY ${ }^{2}$, Greig R. COUSINS ${ }^{1}$ \\ and John R. CARADUS ${ }^{3 *}$ \\ ${ }^{1}$ PGG Wrightson Seeds Ltd, PO Box 69175, Lincoln, 7640, New Zealand \\ ${ }^{2}$ AgResearch Ltd, PB 11008, Palmerston North, 4442, New Zealand \\ ${ }^{3}$ Grasslanz Technology Ltd, PB 11008, Palmerston North, 4442, New Zealand \\ *Corresponding author: john.caradus@grasslanz.com
}

\begin{abstract}
Forage legumes improve both the intake and quality of the diet in pasture-based livestock systems. However, the high protein content of these forages can lead to inefficient nitrogen utilisation in the rumen and to high nitrogen $(\mathrm{N})$ losses in urine and dung. Condensed tannins in forages have been shown to significantly reduce $\mathrm{N}$ leaching and also methane emissions.

The use of classical breeding approaches over more than 50 years has failed to elevate condensed tannins in forage legumes. However, molecular biology approaches have achieved condensed tannin expression in white clover at levels that are biologically significant $(>2 \%$ of dry matter). Results from a field trial in the USA showed that while condensed tannin levels in white clover (Trifolium repens) were similar to those produced by birdsfoot trefoil (Lotus corniculatus), plants did suffer a yield penalty. Protein binding assays were conducted by incubating soluble white clover leaf CTs in a solution containing the protein bovine serum albumin (BSA). The CTs in white clover leaves efficiently precipitated BSA from the supernatant at $\mathrm{pH} 6.5$, and these CT-protein complexes dissociated at $\mathrm{pH} 2.5$.

While the use of genetically modified organisms in New Zealand is regulated, this development has the potential to improve environmental, animal health and animal productivity outcomes from grazed pasture systems.
\end{abstract}

Keywords: Animal health, animal welfare, animal productivity, biotechnology, forages, protein, nitrogen, genetic modification, white clover, proanthocyanidins, prodelphinidins.

\section{Introduction}

The value of legumes, such as white clover (Trifolium repens L.), red clover (T. pratense L.) and lucerne (Medicago sativa L.), to the nitrogen $(\mathrm{N})$ economy of pastures, and to ruminant production, are considerable. However, increasing $\mathrm{N}$ levels in pasture can result in increased losses if the $\mathrm{N}$ is not converted into animal product, namely milk, meat or wool. Protein breakdown in the rumen can result in elevated urinary $\mathrm{N}$ levels
(Pacheco \& Waghorn 2008). Subsequent N loadings in urine patches contain the equivalent of 500 to 1000 $\mathrm{kg} / \mathrm{N} / \mathrm{ha}$ (Haynes \& Williams 1993), and are a major contributor to $\mathrm{N}$ losses from grazed pastures (Cuttle et al. 1992; Ryden et al. 1984).

In some legumes, such as birdsfoot trefoil (Lotus corniculatus), the presence of condensed tannin (CT) in foliage (Harris et al. 1998) has been shown to bind leaf proteins so that they remain intact while passaging through the rumen (Waghorn et al. 1987). Condensed tannins have also been shown to reduce the risk of bloat (Waghorn \& Jones 1989; Burggraaf et al. 2006) and methane emissions (Tavendale et al. 2005; Pellikaan et al. 2011; Hatew et al. 2014). Furthermore, CTs have been shown to improve animal productivity through increased ovulation rates in sheep (Min et al. 2001), increase live weight gain, wool growth, and milk production (Waghorn 2008), alter milk composition (Woodward et al. 1999) and improve anthelmintic effects on gastrointestinal parasites (Waghorn 2008; Villalba et al. 2010).

Development of forage legumes producing high levels of CTs has been viewed as an important objective for reaching industry environmental, animal health and productivity targets. White clover, red clover and lucerne, the predominate forage legumes used in New Zealand pastures, contain little or no CT in their leaves (Marshall et al. 1980), although measurable levels are found in lucerne and clover seed coats and clover flower petals (Goplen et al. 1980; KoupaiAbyazani et al. 1993; Foo et al. 2000). Furthermore, legumes such as birdsfoot trefoil, that do contain good levels of condensed tannins, fail to persist in intensive New Zealand grazing systems. Condensed tannin concentrations of $2-4 \%$ DM are generally required to have a positive impact on animal performance, and therefore influence environmental impacts. More than 50 years of classical plant-breeding approaches have failed to deliver white clover, red clover or lucerne with biologically meaningful levels of $\mathrm{CT}$ in their leaves (Woodfield et al. 1998; Burggraaf et al. 2006). Molecular biology approaches have led to an important breakthrough and demonstrated that, with a single gene 
transformation, condensed tannins can be expressed in white clover and lucerne (Hancock et al. 2012, 2014). The objectives here are to: outline the process of delivering $\mathrm{CT}$ expression to white clover leaves; describe their agronomic field performance; and assess their impact on protein binding and dissociation in the rumen.

\section{Materials and Methods}

\section{Condensed tannin expression in white clover leaves}

The methods to achieve CT expression in white clover leaves have been described in detail by Hancock et al. (2012, 2014). In brief, a transcription factor (TaMYB14-1) that acts as a master switch for $\mathrm{CT}$ synthesis in leaves was originally identified in a species of clover, Trifolium arvense L. (Hancock et al. 2012). The transcription factor was inserted into a binary vector that also included a cauliflower mosaic virus $35 \mathrm{~S}$ promoter (CaMV35S), and a neomycin phosphotransferase gene (NPTII) for selection of transgenic plants. This was introduced into white clover cv. Mainstay using Agrobacterium-mediated T-DNA transfer, and transgenic plants selected on the antibiotic kanamycin.

\section{Trait control and inheritance}

A primary $\left(\mathrm{T}_{0}\right)$ transgenic plant $(\mathrm{CTB})$, with a single TaMYB14-1 insertion, stable Mendelian inheritance ${ }^{1}$, and expressing $1.2 \%$ of condensed tannins in the leaves, was selected for further analysis. This plant was backcrossed to elite non-transgenic white clover genotypes, and the two $\mathrm{T}_{1}$ plants with highest expression were then intercrossed (to produce one $\mathrm{T}_{2}$ generation) and backcrossed to produce three $\mathrm{BC}_{2}$ generations. $\mathrm{BC}_{2}$ progeny were from a $\mathrm{BC}_{1} \mathrm{x}$ Wild Type cross. Testing of TaMYB14-1 inheritance by PCR or DMACA staining showed that it was simply inherited as a single gene according to Mendelian principles in all progenies (data not shown).

Using the progeny from these crosses, a field trial was conducted in La Crosse County, Wisconsin, USA under USDA-APHIS permit requirements. The soil type at the site was a Toddville Silt Loam. Forty $\mathrm{T}_{2}$ and $30 \mathrm{BC}_{2}$ progeny seeds from each cross were germinated and grown under containment glasshouse conditions and, after two weeks, CT-producing genotypes were

1 Mendel's studies yielded three "laws" of inheritance: the law of dominance, the law of segregation, and the law of independent assortment. A dominant trait is a trait whose appearance will always be seen in offspring. A parent may have two distinct alleles for a certain gene, each on one copy of a given chromosome. Mendel's second law, the law of segregation, states that these two alleles will be separated from each other during meiosis. Mendel's third law, the law of independent assortment, states that the way an allele pair gets segregated into two daughter cells during the second division of meiosis has no effect on how any other allele pair gets segregated. (https://education.seattlepi.com/ explanation-mendels-three-laws-through-discussion-meiosis-3838.html) identified using $p$-dimethylaminocinnamaldehyde (DMACA) staining as described (Li et al. 1996). The eight best genotypes (based on high CT expression using DMACA staining) plus two negative controls (nulls) from each of the three $\mathrm{BC}_{2}$ crosses were selected (i.e. 24 positive and 6 negative plants). The best four heterozygous (for TaMYB14-1) and homozygous genotypes plus two negative controls (nulls) were selected from the single $\mathrm{T}_{2}$ cross. Birdsfoot trefoil cultivars Goldie (10 genotypes) and Lotar (10 genotypes) were also included as comparators, as the leaves of these species produce condensed tannins at the range required for therapeutic effects in animals.

The seedlings were planted into the field under a beeproof cage in a randomised block design in May 2018. No irrigation was needed, and no supplemental water was applied to the plants. During the period of the trial $58 \mathrm{~cm}$ of rain fell. However, because of the bee-proof cage, only $46 \mathrm{~cm}$ would have fallen inside the cage. The cage reduced air movement so that the rate of drying of soil inside the cage was considerably slower than that outside the cage.

Measurements of plant morphology (the size of the first fully expanded leaf, width of middle leaflet, petiole length, stolon diameter, and canopy height), were taken in July and August 2018, including herbage samples for dry matter yield and later CT analysis. Soluble and insoluble CTs were extracted from freeze-dried milled leaves as described (Peel \& Dixon 2007; Terrill et al. 1992). Soluble CTs were calculated spectrophotometrically at $640 \mathrm{~nm}$ using epigallocatechin (Indofine Chemical Company, Hillsborough, NJ) for the standard curve. For the insoluble CTs, the absorbance reading was made at 550 $\mathrm{nm}$ and CTs calculated using purified CTs (Zeller et al. 2015) from white clover leaves as the standard. Soluble and insoluble CTs were combined to obtain the total CTs and expressed as a percent of dry matter.

\section{Condensed tannin binding and dissociation of protein}

Condensed tannins were extracted from the leaves of the first generation $\left(T_{1}\right)$ progeny of the white clover CTB line (plant \#657), with the bovine serum albumin (BSA) as the test protein. The CTs were extracted from freeze-dried, finely ground leaf tissue as previously described (Peel \& Dixon 2007). The protein precipitation protocol was as described by Zeller et al (2015) with modifications. Protein was quantitated using a Qubit fluorimeter (ThermoFisher Scientific). The CT-protein binding experiment was performed using three replicates.

\section{Statistical analyses}

Data were analysed using Minitab statistical software. 
Grouping information used the Fisher LSD method with $95 \%$ confidence limits to determine differences between means.

\section{Results}

\section{Trait control and inheritance}

The field trial demonstrated that CT levels in white clover leaves can achieve levels similar to that produced by birdsfoot trefoil. Notably some $\mathrm{T}_{2}$ progeny, homozygous for the TaMYB14-1 gene, accumulated total CTs of $2 \%$ DM, with the average being $1.87 \%$ (Table 1). However, a yield penalty and reduced plant stature was observed in plants producing the highest $\mathrm{CTs}$ (Table 1). The $\mathrm{BC}_{2}$ family that drives the negative relationship in the $\mathrm{BC}_{2}$ overall produced one plant with low yield $(<5 \mathrm{~g})$ and with $\sim 1.5 \% \mathrm{CT}$ content (Figure 1$)$. When that genotype was removed from the dataset, the relationship between yield and CT level became neutral to slightly positive (solid line in Figure 1). The other two $\mathrm{BC}$ families had either a positive or only a slightly negative relationship between yield and $\mathrm{CT}$ content. In the case of one $\mathrm{BC}_{2}$ family there were plants in the $25 \mathrm{~g}$ yield range with $\mathrm{CT}$ levels close to $1 \%$. The comparison of CT content and yield indicates that some genotypes could be selected to create a population to improve both yield and CT content (Figure 1).

\section{Condensed tannin binding and dissociation of protein}

Protein binding assays were conducted by incubating soluble white clover leaf CTs in a solution containing BSA at pH6.5. Binding of BSA by CTs is expected to result in the formation of an aggregate, which can be centrifuged into the pellet (leaving undetectable amounts of protein in the supernatant). This procedure showed that white clover leaf CTs efficiently precipitated BSA from the supernatant (Figure 2A) into the pellet (Figure

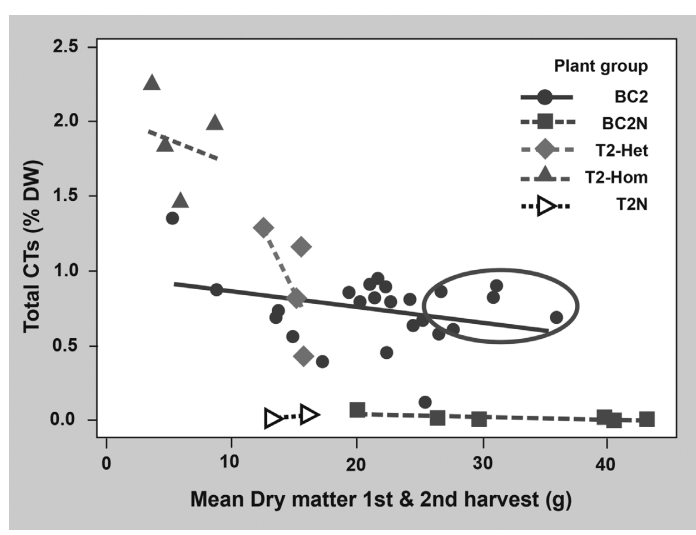

Figure 1 Total CT content (\%DM) and dry matter yield for individual plants. Those encircled would be the typical genotypes selected to improve both yield and $\mathrm{CT}$ content. BC2 progeny were from a BC1 $x$ Wild Type cross. The 24 plants denoted by circles were TaMYB14-1 positive (8 from each of 3 crosses) and the 6 plants denoted by squares were the null segregants (BC2N) (2 from each of 3 crosses). T2 progeny were from a T1 $x$ T1 cross. The 4 plants denoted by diamonds were heterozygous for TaMYB14-1 (T2-Heterozygous) and the 4 plants denoted by triangles were homozygous (T2-Homozygous). The 2 plants denoted by open triangles were null segregants from the T2 cross.

2B). Conversely, upon resuspension of the pellet in an acidic solution ( $\mathrm{pH} 2.5$ ), the CT-protein complexes dissociated and the BSA disappeared from the pellet and reappeared in the supernatant (Figure 2C). These results provide the first evidence that white clover $\mathrm{CTs}$ can complex with proteins at $\mathrm{pH} 6.5$ and then release them at $\mathrm{pH} 2.5$, the $\mathrm{pH}$ of the rumen and the abomasum, respectively. Protein release is necessary for absorption in the small intestine.

Table 1 Mean total condensed tannin (CT), shoot dry weight, leaflet width, petiole length, stolon diameter and canopy height for white clover groups based on pedigree compared with birdsfoot trefoil.

\begin{tabular}{|c|c|c|c|c|c|c|}
\hline Plant group & $\begin{array}{l}\text { Total CT } \\
\text { (\%DM) }\end{array}$ & $\begin{array}{l}\text { Dry weight } \\
\text { (g/plant) }\end{array}$ & $\begin{array}{l}\text { Leaflet width } \\
\qquad(\mathrm{mm})\end{array}$ & $\begin{array}{l}\text { Petiole length } \\
(\mathrm{mm})\end{array}$ & $\begin{array}{l}\text { Stolon diameter } \\
(\mathrm{mm})\end{array}$ & $\begin{array}{c}\text { Canopy height } \\
(\mathrm{mm})\end{array}$ \\
\hline $\mathrm{T}_{2}$ homozygotes & $1.87^{\mathrm{a}}$ & $5.7^{c}$ & $17^{c}$ & $97^{\mathrm{b}}$ & 2.8 & $172^{\mathrm{b}}$ \\
\hline $\mathrm{T}_{2}$ heterozygotes & $0.92^{\mathrm{c}}$ & $14.7^{\mathrm{bc}}$ & $18^{c}$ & $122^{\mathrm{ab}}$ & 2.7 & $182^{a b}$ \\
\hline $\mathrm{T}_{2}$ null & $0.01^{d}$ & $14.5^{\mathrm{bc}}$ & $23^{a}$ & $155^{a}$ & 3.1 & $200^{\mathrm{ab}}$ \\
\hline $\mathrm{BC}_{2} \mathrm{CT}$ & $0.73^{\mathrm{c}}$ & $21.8^{\mathrm{b}}$ & $21^{b}$ & $130^{\mathrm{a}}$ & 2.7 & $179^{b}$ \\
\hline $\mathrm{BC}_{2}$ null & $0.01^{d}$ & $33.2^{\mathrm{a}}$ & $24^{\mathrm{a}}$ & $143^{a}$ & 2.8 & $218^{a}$ \\
\hline Lotus & $1.23^{\mathrm{b}}$ & $21.2^{\mathrm{b}}$ & $\mathrm{nm}$ & $\mathrm{nm}$ & $\mathrm{nm}$ & $\mathrm{nm}$ \\
\hline P-value & $<0.001$ & $<0.001$ & 0.001 & 0.059 & ns & 0.045 \\
\hline
\end{tabular}




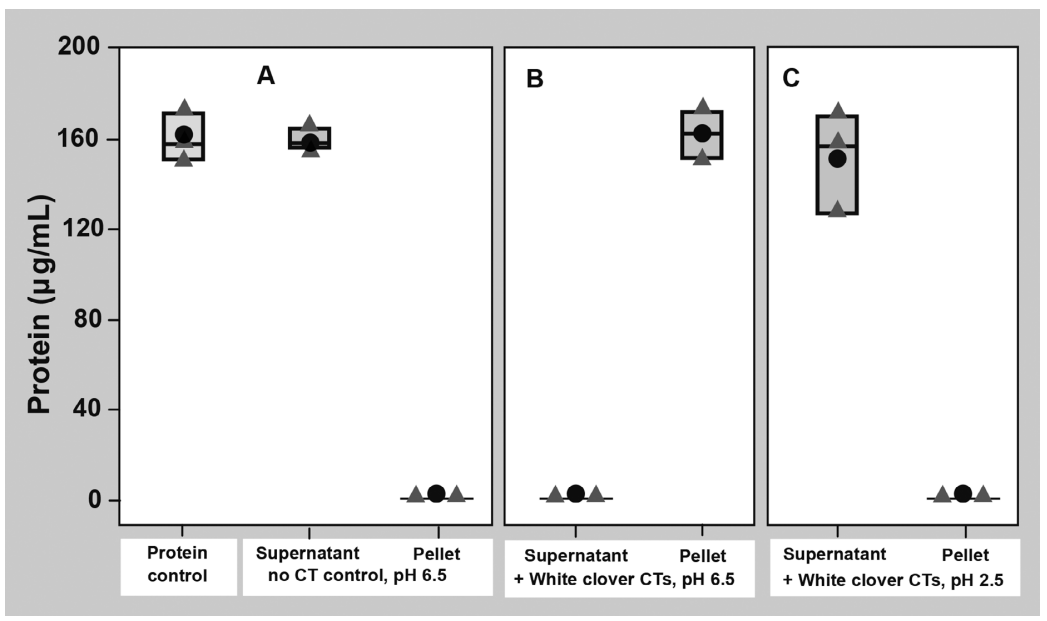

\section{Figure 2}

Protein (bovine serum albumin) recovered from either the supernatant or pellet after incubation without $(A)$ or with (B-C) white clover condensed tannins at $\mathrm{pH} 6.5$ (A-B) and at $\mathrm{pH}$ 2.5 (C). The CT-protein binding experiment was performed in three replicates. The triangles represent individual data points and the dark-coloured circles show the mean of each treatment.

\section{Discussion}

Condensed tannin levels above 2\% of DM are considered biologically significant (Waghorn et al. 1990), and expression of the TaMYB14-1 transcription factor in white clover has shown that it is possible to achieve $\mathrm{CT}$ expression in leaves that are equivalent or greater than those found in birdsfoot trefoil. Trait expression was further enhanced in homozygous genotypes of the $T_{2}$ generation, which were produced by pairwise crossing of high CT-expressing $\mathrm{T}_{1}$ plants. These levels of CT expression in white clover are expected to sequester forage protein away from microbes in the rumen, and as a result, reduce $\mathrm{N}$ losses to the environment.

However, plant morphology and dry matter yield were significantly lower in high CT plants compared with untransformed null segregants in field conditions. A few plants produced acceptable yields and CT levels. Genotypes such as these suggest that the yield penalty may be overcome through selection. Future breeding will focus on improving yield while maintaining CT levels above $2 \%$ of DM but it is appropriate to reflect on factors that may have led to this yield depression.

Transgenesis is often used to deliver traits that have the potential to improve plant yield such as disease resistance, and drought or salt tolerance. In the current study, the transgenic trait was aimed at improving forage plant quality with resulting improvements in environmental benefits, stock health and production. However, this resulted in significant yield reductions particularly in plants homozygous for the transgene transcription factor. This yield depression may have been due to the trait itself, the promoter used, and/or other elements of the gene construct used, or possible inbreeding to achieve homozygosity.

Most published studies on the impact of transgenic elements on plant yield have shown little negative effect
(Dong et al. 2006) but yield depression may occur in some instances. For example, transgenic tomato plants that express the coat protein (CP) of the common (U1) strain of tobacco mosaic virus (TMV) were produced from cultivar VF36 using gene-transfer techniques (Nelson et al. 1988). These authors concluded that yields from one $\mathrm{CP}$-expressing line were equal to that of the uninoculated VF36 plants suggesting that expression of the $\mathrm{CP}$ gene does not intrinsically cause yield depression. There are also examples where high expression of a metabolite through transgenesis can lead to yield reductions. Bohmert et al. (2000) successfully expressed the three enzymes encoding for polyhydroxybutyrate (PHB) in Arabidopsis thaliana (L.) using the CaMV35S promoter and achieved levels of PHB up to about $40 \%$ of their dry weight. However, the high levels of polymer produced resulted in severe yield depression. Kasuga et al. (1999) demonstrated that the use of the strong constitutive CaMV35S promoter to drive expression of a transcription factor (DREB1A) also resulted in growth retardation under normal growing conditions. In contrast, expression of DREB1A from the stress-inducible rd29A promoter gave rise to minimal effects on plant growth while providing an even greater tolerance to stress conditions than did expression of the gene from the CaMV35S promoter. Indeed, these results suggest that the use of CaMV35S promoter in transgenesis can result in a range of pleiotropic phenotypic responses. However, plant responses can be varied due to a range of factors. For instance, Tata et al (2016) also used CaMV35S promoter in expressing geranylgeranyl pyrophosphate synthase (GGPS), a key enzyme for the production of biosynthetic metabolites in plants, and have reported enhanced desirable agronomic traits such as increased plant height, shoot and root biomass as well as greater seed yield relative to the control. 
In our study, it was apparent that a yield penalty occurred as levels of CTs exceeded $1 \%$ of dry weight. Our previous studies focused mainly on elevating CT levels in white clover leaves rather than on enhancing plant growth and yield so will be our next focus of research. Additionally, white clover can be very sensitive to inbreeding depression (William 1987). The greatest depression of dry matter yield occurred when the TaMYB14 gene was homozygous, which may be related to inbreeding effects. There is little doubt that inbreeding in white cover can reduce yield and subsequent ecological fitness (Cousins \& Woodfield 2006).

The programme has determined that the families with high foliar CT concentrations in the glasshouse also have high CT expression under field conditions (data not shown). White clovers with CT expression have been developed and field tested in containment in the USA but their use in New Zealand is regulated as they are genetically modified organisms. However, this development has the potential to improve environmental, animal health and animal productivity outcomes for pastoral agriculture.

The effective protein binding at neutral $\mathrm{pH}$ followed by release at low $\mathrm{pH}$ by the foliar white clover CTs produced from the TaMYB14 transcription factor (Figure 2) suggests that these tannins are likely to produce a range of environmental benefits leading to reduced nitrogen losses through urine (Theodoridou et al. 2010) and possibly methane production from ruminants (Huyen et al. 2016). Recently, the Ministry for the Environment published "Environment Aotearoa 2019" (https://www.mfe.govt.nz/EnvironmentAotearoa-2019), which prioritised the nine most important issues affecting the health of New Zealand's environment. These included: waterways in farming areas are polluted by excess nutrients, pathogens, and sediment; and that New Zealand has high greenhouse gas emissions per person. The deployment of CTs in New Zealand's pasture systems has the potential to reduce the impact of pastoral farming with ruminants on the environment.

\section{Conclusions/Practical implications/ Relevance}

The isolation of a key transcription factor that regulates $\mathrm{CT}$ expression has led to the development of white clover with close to $2 \%$ CTs in leaves. Normally, white clover only expresses CTs in leaf trichomes and flowers while a closely related Trifolium species (T. arvense) accumulates significant amounts of CTs in leaves. Genetic transformation and expression of the $T$. arvense transcription factor, TaMYB14-1, in white clover resulted in the stable accumulation of CTs in leaves. Overcoming the yield penalty that has been identified will be the focus of ongoing research.

In addition to providing a range of beneficial impacts on animal production, health and welfare, and improved product quality, CT-expressing white clovers are a potential solution for reducing $\mathrm{N}$ losses and methane production from ruminants. However, the challenge for New Zealand is how to accommodate genetically modified plants in New Zealand farming systems and how to best engage in public discussion of the risks and benefits.

\section{ACKNOWLEDGEMENTS}

This research was funded by the Primary Growth Partnership investment programme of the New Zealand Ministry for Primary Industries in partnership with PGG Wrightson Seeds and Grasslanz Technology. We thank Jerome Demmer (Halcyon Consulting, New Zealand) for intellectual input, and Rupinder Kaur and Matt Francis (PGG Wrightson Seeds Ltd) for technical assistance. We are also grateful to Wayne Zeller of ARS, USDA, Madison, WI, for the purification of CTs (from the T0 white clover leaves), used as standard in CT quantitation, and to Karl Fraser and Arvind Subbaraj (Food and Bio-Based Products Team, AgResearch) for the purification of CTs (from the T1 progeny) used in protein binding experiments. The field trials in the USA were established and managed by staff from Forage Genetics International West Salem, WI USA research station, with assistance from Tony Stratton and Margaret Stratton, AgResearch USA.

\section{REFERENCES}

Bohmert K, Balbo I, Kopka J, Mittendorf V, Nawrath C, Poirier Y, Tischendorf G, Trethewey RN, Willmitzer L. 2000. Transgenic Arabidopsis plants can accumulate polyhydroxybutyrate to up to $4 \%$ of their fresh weight. Planta 211: 841- 845.

Burggraaf VT, Woodward SL, Woodfield DR, Thom ER, Waghorn GC, Kemp PD. 2006. Morphology and agronomic performance of white clover with increased flowering and condensed tannin concentration. New Zealand Journal of Agricultural Research 49: 147-155.

Cousins G, Woodfield D. 2006. Effect of inbreeding on growth of white clover. In: Mercer, CF Ed. Breeding for Success: Diversity in Action. Proceedings of the 13th Australasian Plant Breeding Conference, Christchurch, New Zealand 18-21 April 2006. pp. 568-572.

Cuttle SP, Hallard M, Daniel G, Scurlock RV. 1992. Nitrate leaching from sheep-grazed grass/clover and fertilized grass pastures. Journal of Agricultural Science (Camb.) 119: 335-343.

Dong HZ, Li WJ, Tang W, Li ZH, Zhang DN. 2006. Effects of genotypes and plant density on yield, yield 
components and photosynthesis in Bt transgenic cotton. Journal of Agronomy and Crop Science 192: 132-139.

Foo LY, Lu Y, Molan AL, Woodfield DR, McNabb WC. 2000. The phenols and prodelphinidins of white clover flowers. Phytochemistry 54: 539-548.

Goplen BP, Howarth RE, Sarkar SK, Lesins K. 1980. A search for condensed tannins in annual and perennial species of Medicago, Trigonella, and Onobrychis. Crop Science 20: 801-804.

Hancock KR, Collette V, Fraser K, Greig M, Xue H, Richardson K, Jones C, Rasmussen S. 2012. Expression of the R2R3-MYB transcription factor TaMYB14 from Trifolium arvense activates proanthocyanidin biosynthesis in the legumes Trifolium repens and Medicago sativa. Plant Physiology 159: 1204-1220.

Hancock K, Collette V, Chapman E, Hanson K, Temple S, Moraga R, Caradus J. 2014. Progress towards developing bloat-safe legumes for the farming industry. Crop and Pasture Science http://dx.doi. org/10.1071/CP13308

Harris SL, Clark AD, Laboyrie PJ. 1998. Birdsfoot trefoil-An alternative legume for New Zealand dairy pastures. Proceedings of the New Zealand Grassland Association 60: 99-103.

Hatew B, Hayot Carbonero C, Stringano E, Sales LF, Smith LMJ, Mueller-Harvey I, Hendriks WH, Pellikaan WF. 2014. Diversity of condensed tannin structures affects rumen in vitro methane production in sainfoin (Onobrychis viciifolia) accessions. Grass and Forage Science 70: 474-490.

Haynes RJ, Williams PH. 1993. Nutrient cycling and soil fertility in the grazed pasture ecosystem. Advances in Agronomy 49: 119-199.

Huyen NT, Fryganas C, Uittenbogaard G, MuellerHarvey I, Verstegen MWA, Hendriks WH, Pellikaan WF. 2016. Structural features of condensed tannins affect in vitro ruminal methane production and fermentation characteristics. Journal of Agricultural Science 154: 1474-1487

Kasuga M, Liu Q, Miura S, Yamaguchi-Shinozaki K, Shinozaki K. 1999. Improving plant drought, salt, and freezing tolerance by gene transfer of a single stress-inducible transcription factor. Nature Biotechnology 17: 287-291.

Koupai-Abyazani MR, McCallum J, Muir AD, Lees GL, Bohm BA, Towers GHN, Gruber MY. 1993. Purification and charcaterization of a proanthocyanidin polymer from seed of alfalfa (Medicago sativa $\mathrm{Cv}$. Beaver). Journal of Agricultural Food and Chemistry 41: 565-569.

Li YG, Tanner G, Larkin P. 1996. The DMACA-HClProtocol and the threshold proanthocyanidin content for bloat safety in forage legumes. Journal of the Science of Food and Agriculture 70: 89-101.
Marshall DR, Broué P, Grace J, Munday J. 1980. Tannins in pasture legumes. The annual and perennial Medicago species. Australian Journal of Experimental Agriculture 21: 47-50.

Min BR, McNabb WC, Kemp PD, McDoland MF, Barry TN. 2001. The effect of condensed tannins in Lotus corniculatus upon reproductive efficiency and wool production in ewes during autumn. Animal Feed Science and Technology 92: 185-202.

Nelson RS, McCormick SM, Delannay X, Dubé P, Layton J, Anderson EJ, Kaniewska M, Proksch RK, Horsch RB, Fraley RT, Beachy RN. 1988. Virus tolerance, plant performance of transgenic tomato plants expressing coat protein from tobacco mosaic virus. Bio/Technology 6: 403-409.

Pacheco D, Waghorn GC. 2008. Dietary nitrogen definitions, digestion, excretion and consequences of excess for grazing ruminants. Proceedings of the New Zealand Grassland Association 70: 107-116.

Peel G J, Dixon RA. 2007. Detection and quantification of engineered proanthocyanidins in transgenic plants. Natural Products Communications 2: 1009-1014.

Pellikaan WF, Stringano E, Leenaars J, Bongers DJGM, van Laar-van Schuppen S, Plant J, Mueller-Harvey I. 2011. Evaluating effects of tannins on extent and rate of in vitro gas and $\mathrm{CH}_{4}$ production using an automated pressure evaluation system. Animal Feed Science and Technology 166-167: 377-390.

Ryden JC, Ball PR, Garwood EA. 1984. Nitrate leaching from grassland. Nature 311: 50-53.

Tata SK, Jung J, Kim YH, Choi JY, Jung JY, Lee IJ, Shin JS, Ryu, SB. 2016. Heterologous expression of chloroplast-localized geranylgeranyl pyrophosphate synthase confers fast plant growth, early flowering and increased seed yield. Plant Biotechnology Journal 14: 29-39

Tavendale $\mathrm{MH}$, Meagher LP, Pacheco D, Walker N, Attwood GT, Sivakumaran S. 2005. Methane production from in vitro rumen incubations with Lotus pedunculatus and Medicago sativa, and effects of extractable condensed tannin fractions on methanogenesis. Animal Feed Science and Technology 123-124: 403-419.

Terrill TH, Rowan AM, Douglas GB, Barry TN. 1992. Determination of extractable and bound condensed tannin concentrations in forage plants, protein concentrate meals and cereal grains. Journal of the Science of Food and Agriculture 58: 321-329.

Theodoridou K, Aufrere J, Andueza D, Morvan A, Picard F, Stringano E, Pourrat J, Mueller-Harvey I, Baumont R. 2011. Effect of plant development during first and second growth cycle on chemical composition, condensed tannins and nutritive value of three sainfoin (Onobrychis viciifolia) varieties and lucerne. Grass and Forage Science 66:402-414. 
Villalba JJ, Provenza FD, Hall JO, Lisonbee LD. 2010. Selection of tannins by sheep in response to gastrointestinal nematode infection. Animal Science 88:21892198. Waghorn GC 2008. Beneficial and detrimental effects of dietary condensed tannins for sustainable sheep and goat production - Progress and challenges. Animal Feed Science and Technology 147: 116-139.

Waghorn GC, Jones WT. 1989. Bloat in cattle. 46. Potential of dock (Rumex obtusifolius) as an antibloat agent for cattle. New Zealand Journal of Agricultural Research 32: 227-235.

Waghorn GC, Jones WT, Shelton ID, McNabb WC. 1990. Condensed tannins and the nutritive value of herbage. Proceedings of the New Zealand Grassland Association 51: 171-176.

Waghorn GC, Ulyatt MJ, John A, Fisher MT. 1987. The effect of condensed tannins on the site of digestion of amino acids and other nutrients in sheep fed on lotus. British Journal of nutrition 57: 115-126.
Williams, WM. 1987. Genetics and breeding. In: Baker MJ \& Williams WM Eds. White Clover. CAB International, Wallingford, U.K. pp. 343-419.

Woodfield DR, McNabb W, Kennedy L, Cousins GR, Caradus JR. 1998. Floral and foliar tannin content in white clover. Proceedings of the Trifolium Conference 15: 19.

Woodward SL, Auldist MJ, Laboyrie PJ, Jansen EBL. 1999. Effect of Lotus corniculatus and condensed tannins on milk yield and milk composition of dairy cows. Proceeding of New Zealand Society of Animal Production 59: 152-155.

Zeller WE, Sullivan ML, Mueller-Harvey I, Grabber JH, Ramsay A, Drake C, Brown RH. 2015. Protein precipitation behavior of condensed tannins from Lotus pedunculatus and Trifolium repens with different mean degrees of polymerization. Journal of Agricultural and Food Chemistry 63: 11601168. 
